\title{
Experimental investigation and Analysis on effect of fiber orientation on mechanical properties of synthetic and natural fiber reinforced hybrid composite
}

DOI:10.36909/jer.ICMMM.15719

\author{
Pradeep Devaenthiran*1, Kumar Murugesan ${ }^{2}$, Sangaravadivel Palaniappan ${ }^{3}$ \\ ${ }^{1,3}$ Department of Mechanical Engineering, Bannari Amman Institute of Technology, \\ Sathyamangalam, Erode, Tamilnadu, 638451, India. \\ ${ }^{2}$ Department of Mechanical Engineering, KPR Institute of Engineering and Technology, \\ Arasur, Coimbatore, Tamilnadu, 641407, India. \\ *Corresponding Author: adpradeep@live.com
}

\begin{abstract}
Automobile bumper is an essential component that is commonly used to absorb the impact load during vehicle collisions, in fact it saves lives at such occurrences.In order to withstand the impact load, and the bumper deforms itself during collision and protects the passengers by havingthe proper cross section and the material selection. In this way, the study explores the mechanical characterization of fabricated composite and its structural analysis. Impact conditions have to be studied for improving the mechanical properties of the bumper during collision. The material chosen for analysis is jute and Glass fiber reinforced hybrid epoxy composite, considering its light weight and strength characteristics. Composites with two different fibre orientations $\left(45^{\circ} / 90^{\circ}\right)$ are fabricated using Hydraulic Compression Moulding technique. From experimental observations of jute and glass fiber reinforced hybrid composites, the orientation has significant effect on the structural and mechanical properties. The results are validated using the simulation of a bumper by impact modelling using CATIA software and impact analysis is carried out using ANSYS.
\end{abstract}

Keywords: Bumper; Mechanical characterization; Impact analysis; Jute fiber; Glass fiber. 


\section{INTRODUCTION}

An automobile bumper is attached at front and back, apparently intended to support an effect without harming the vehicle's security frameworks. They are not equipped for decreasing injury to vehicle inhabitants in high velocity impacts, yet are progressively being intended to less injury to people. Front and back metal bar,guards and became standard component on all vehicles since 1925. The present plastic bumpers and belt frameworks are stylishly satisfying, at the same time offering benefits to the both designers and customers. Most of currently used vehicle bumper are made of thermoplastic olefins (TPOs), polyesters, polycarbonates, polyurethanes, polyamides, polypropylene, or mix of these with glass filaments, to have better strength and underlying inflexibility. Plastic guards contain fortifications that permit them to be as effective and safe as metals, while being more affordable to supplement their metal counterparts.

\section{Composites}

Composites materials are utilized in different applications to have selective mechanical properties and are produced for specific application. The improvement in design and fabrication methods is a major advancement since existence of composite materials. They have a scope of benefits over other customary materials because of their mechanical properties making them suitable for wide range of structural applications. 
Table 1 Natural Fibers - Physical and Mechanical properties [John et al.]

\begin{tabular}{|l|l|l|l|l|}
\hline \multicolumn{1}{|c|}{ Fibre } & \multicolumn{1}{|c|}{ Density in $\frac{\boldsymbol{g}}{\boldsymbol{c c}}$} & $\begin{array}{c}\text { Tensile Strength } \\
\mathbf{( M P a )}\end{array}$ & $\begin{array}{c}\text { Elongation at } \\
\text { break (\%) }\end{array}$ & $\begin{array}{c}\text { Young's } \\
\text { Modulus (GPa) }\end{array}$ \\
\hline Kenaf & ---- & 930 & 1.60 & 53 \\
\hline Date Palm & $1-1.20$ & $97-196$ & $2-4.50$ & $2.50-5.40$ \\
\hline Bagasse & 1.25 & 290 & ---- & 17 \\
\hline Hemp & 1.48 & 690 & 1.60 & 70 \\
\hline Curaua & 1.40 & $500-1150$ & $3.70-4.30$ & 11.80 \\
\hline Bamboo & $0.60-1.10$ & $140-230$ & ---- & $11-17$ \\
\hline Jute & 1.30 & $393-773$ & $1.50-1.80$ & 26.50 \\
\hline Banana & 1.35 & 500 & 5.90 & 12 \\
\hline Coir & 1.20 & 175 & 30 & $4-6$ \\
\hline Flax & 1.50 & $345-1035$ & $2.70-3.20$ & 27.60 \\
\hline Cotton & $1.50-1.60$ & $287-597$ & $7-8$ & $5.50-12.60$ \\
\hline
\end{tabular}

Fibers used in polymer composites are either engineered or man-made filaments. Most utilized synthetic fibers are glass, aramid and carbon. Among reinforcements, natural fibers have acquired importance in all types of composites, especially polymer matrix composites. As of late, because of the developing worldwide energy crisis and biological dangers, they have pulled in more examination interests. Benefits associated with natural fibers are their accessibility, biodegradable, sustainable, ecological, amicable, ease, low thickness, low energy utilization, good thermal properties and non-abrasive nature. Table 1 lists few natural fibers available and their properties.

Among different characteristic plant fibers, jute fiber has an incredible potential like low thickness, low prolongation at break and is utilized as support in polymer composites. For many years jute has been utilized for making ropes, beds, packs and so on. Jute is richly accessible in regions of peninsular India. In comparison with other natural fibers, jute is highly durable and better angle proportion. Cellulose content in jute provide its composites high effective tensile and flexural properties contrast to other fiber filaments like sisal, pineapple, coir, and banana. The inherent solidness and strength of glass fiber draws the consideration of the world. Because of various stacking conditions endured during its service life, composites with equivalent reinforcement material are not providing better outcomes. 
Hybrid composites are the best solution to tackle those issues for such applications.

A mix of at least two unique kinds of fiber in which one balances the insufficiency of another fiber is called hybrid composite. The reason is to build a material that will hold the advantages of its constituents yet their disadvantages are compensated by another fiber. The mechanical properties, orientation, physical content of fibers, elastic and strength properties of the matrix, fibre-matrix interfaces, fiber-matrix bond are parameters that influence hybrid composite properties. To get specific application favored properties, material execution changes with the fiber substance and fiber orientation under given stacking conditions are to be realized.

\section{LITERATURE REVIEW}

In the recent years, biodegradability, hardness, flexibility, availability, low cost, light weight features in natural fibre based polymer composites attracts more experimentation done on these types of fibers. Biswas et al. experimented coir reinforced epoxy composites and found that its mechanical behavior is affected by length. Hardness decreased with the increase in fibre length beyond $20 \mathrm{~mm}$. Sanjay et al. studied the effect of incorporating natural fibers with GFRP. With improved properties, suggested its use as an alternate material. Sharmin et al. fabricated and studied jute and e- glass fiber reinforced hybrid composites hand laid followed by compression molding. Tensile properties improved due to fabrication method employed and reported that it can be enhanced further by chemical treatment of jute fiber. Hybridization of jute and glass fiber resulted in better tensile and water absorption properties when compared to use of jute fiber alone was reported by Sergio Monteiro et al. Acharya et al. investigated the stacking sequence effect on the tribological behaviour of hybrid epoxy composite and observed that the proper weight percentage of jute and glass fibers improves its mechanical properties. Chawla and Bastos investigated the effect of fibre volume fraction on mechanical properties of untreated jute fibers reinforced in unsaturated polyester resin. Braga et al. investigated and compared raw jute and glass fiber reinforced epoxy hybrid composites for their thermal and mechanical properties. On decreasing the percentage of jute fiber, the 
density of the composite materials increased. Chandekar et al. investigated on water absorption characteristics of jute glass reinforced hybrid composite. In addition to high stiffness and impact strength, Jute reinforced glass epoxy composite possesses good damage tolerance, lighter weight, and better surface finish. Hence, higher fuel efficiency would employ them in applications like automobiles and railway coaches and sporting goods such as skis, canoe helmets. Dehury et al. studied on the Mechanical characteristics of Jute-Epoxy Laminated Composite and observed that the Fiber orientation enhanced the tensile and flexural properties of laminates. Hybridization with Glass fiber enhanced the moisture absorption capability to a great extent in addition to mechanical properties. Rafiquzzaman et al. investigated on Jute and Glass Fiber Based Composite for its use in skateboard and observed that the Jute glass fiber based composite improved tensile properties when single reinforced is used. Flexural and impact tests also exhibit similar results. The performance test results were compared for jute- glass fiber based polymer skateboard and Canadian hard rock maple wood skateboard. Composite exhibits better significance for the sports component application. Indra et al. studied the composites mechanical properties reinforced with Jute, Pineapple leaf and Glass fiber in 1:1:1 ratio. Two matrix materials polyester and epoxy resin were used. The tensile, flexural and impact properties of both the polyester and epoxy composites were found to be increased with fiber content. Among the two matrix elements used, polyester has better properties than epoxy composites. Kumar et al. investigated the usage of composites for safety helmet used in industries. The flexural strength increased with weight percentage of jute fiber. The glass epoxy composite shown better impact strength than jute epoxy composite. Dilfi et al. studied the Effect of Surface Modification of Jute Fiber on the Mechanical Properties and Durability of Jute Fiber- Reinforced Epoxy Composites and observed that the combined alkali and silane treatment improved the properties than the individual treatments. Sanjay et al. studied on Natural Glass Fiber Reinforced Polymer Hybrid Composites and observed to exhibit better mechanical properties. Incorporating different 
natural fiber polymers with synthetics lead to increase its use displacing non-renewable materials. Harpreet et al. studied on jute fiber explored its usage as green composites for automotives, toys and furniture and not limiting it to textile applications. Improvement of mechanical strength of jute fiber polymer composites needs more research. Wang et al. investigated the Effect of Jute Fiber Modification on Mechanical Properties. They observed that tensile strength, elongation at break, and interfacial adhesion of chemically treated jute fibers are better than the raw jute composites. Indra et al. investigated the properties of Jute, Pineapple leaf and Glass Fiber Reinforced Hybrid Composites. Tensile and flexural properties of the composites were found to be increased with fiber content, confirming the reinforcing action of the fibers. The epoxy composite reinforced with Jute, Pineapple leaf and Glass is found to have better strength to weight ratio.

With this profound literature review, the present work attempts to investigate the mechanical characterization and structural analysis of hybrid composite reinforced with jute and glass fiber. The effect of fibre orientation on the mechanical properties will be explored both experimentally and analytically.

\section{Present work objectives}

The present work concentrates on the following points:

- To fabricate a hybrid composites of bi-directional glass and jute reinforced hybrid composite.

- To study mechanical properties under the influence of fiber orientation, both experimentally and analytically.

- To design a bumper using CATIA software and to analyzeits structure using ANSYS software. 


\section{Composite Fabrication Process}

The fabrication work is carried out by hand layup process followed Hydraulic Compression Moulding technique. Epoxy is used as matrix material with bi-directional jute and the E-glass fibers acts as reinforcement for matrix. The weight percentage mixing of epoxy resin and hardener is in the ratio of 10:1. Composites with fibre orientations as $45^{\circ}$ and $90^{\circ}$ are fabricated. Figure 1 represents bi-directional jute and glass fibre respectively. Subsequently, the required specimens for testing dimensions are cut for characterization and testing.

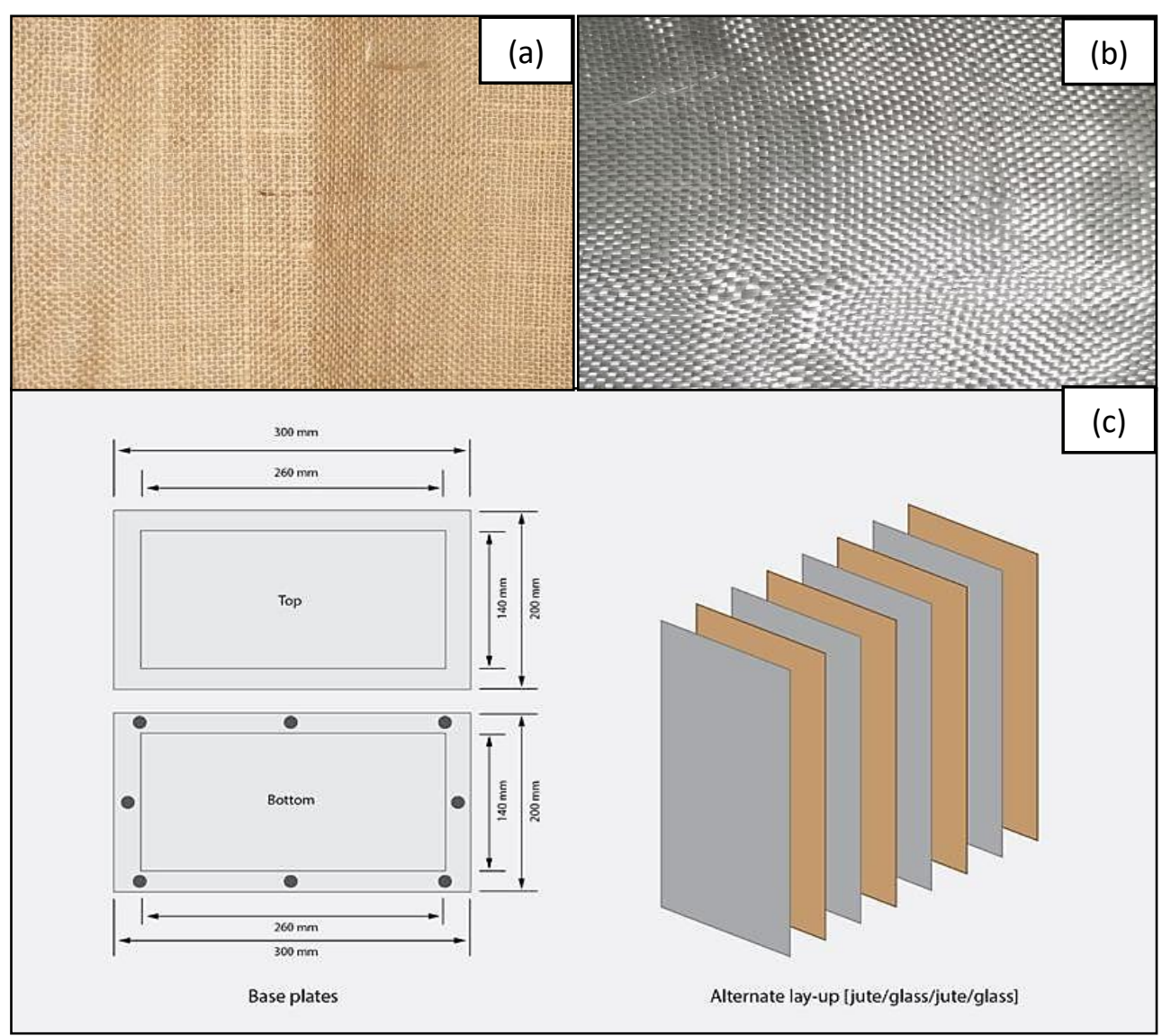

Figure.1 (a) Jute bidirectional fiber and (b) Glass bidirectional fiber (c) Proposed arrangement of reinforcements for composite fabrication 


\section{Mechanical characterization of hybrid composite}

Tensile Test

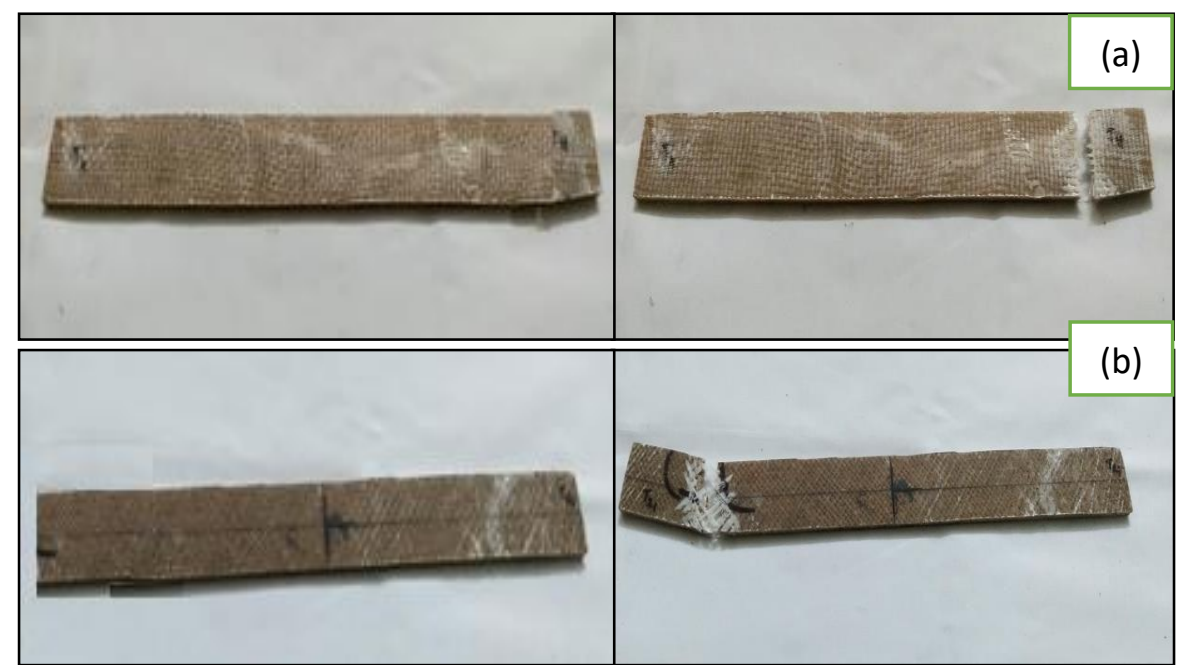

Figure 2 Specimens before and after tensile test a) $90^{\circ}$ orientation b) $45^{\circ}$ orientation

The tensile test for the fabricated composite specimen is fabricated as per ASTM D3039-76 standard. Figure $2 \mathrm{a}$ and $2 \mathrm{~b}$ shows the test specimens reinforced with bi-directional jute and glass fiber epoxy hybrid composites before and after testing. Figure 3 depict the machine and loading arrangement for tensile test.

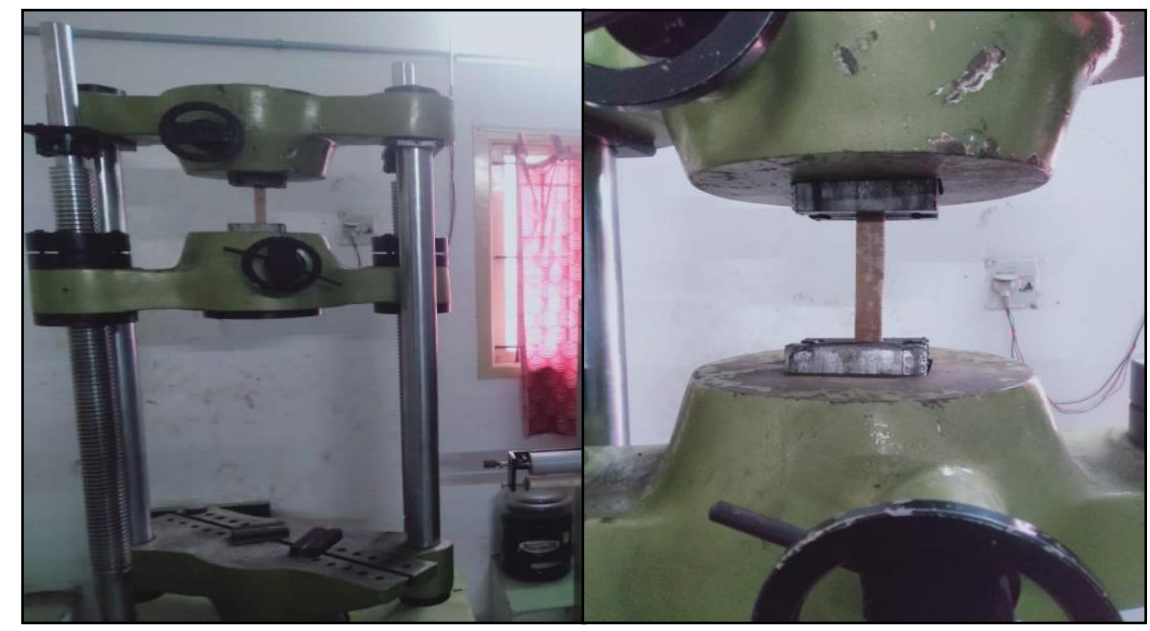

Figure 3 Loading arrangements for tensile test 


\section{Flexural Test}

The ability of material to withstand bending stress/load before reaching its breaking point can be found using flexural test. The test is based on three-point bend principle using INSTRON 1195 machine as shown in Figure 4. The specimen with span $40 \mathrm{~mm}$ and cross-head is moved at a speed of $2 \mathrm{~mm} / \mathrm{min}$. Figure 5 shows experimental loading arrangement for flexural test.
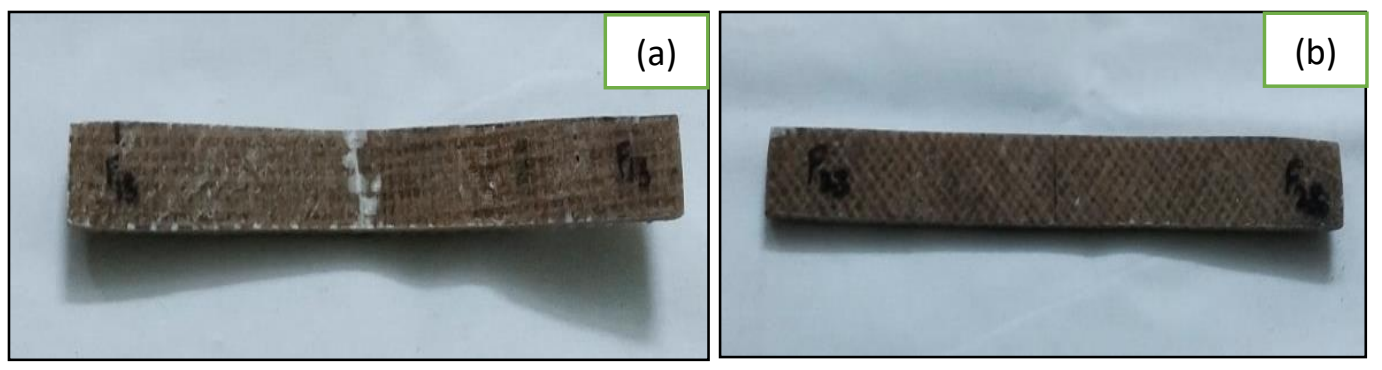

Figure 4 Specimens after flexural test a) $90^{\circ}$ orientation b) $45^{\circ}$ orientation

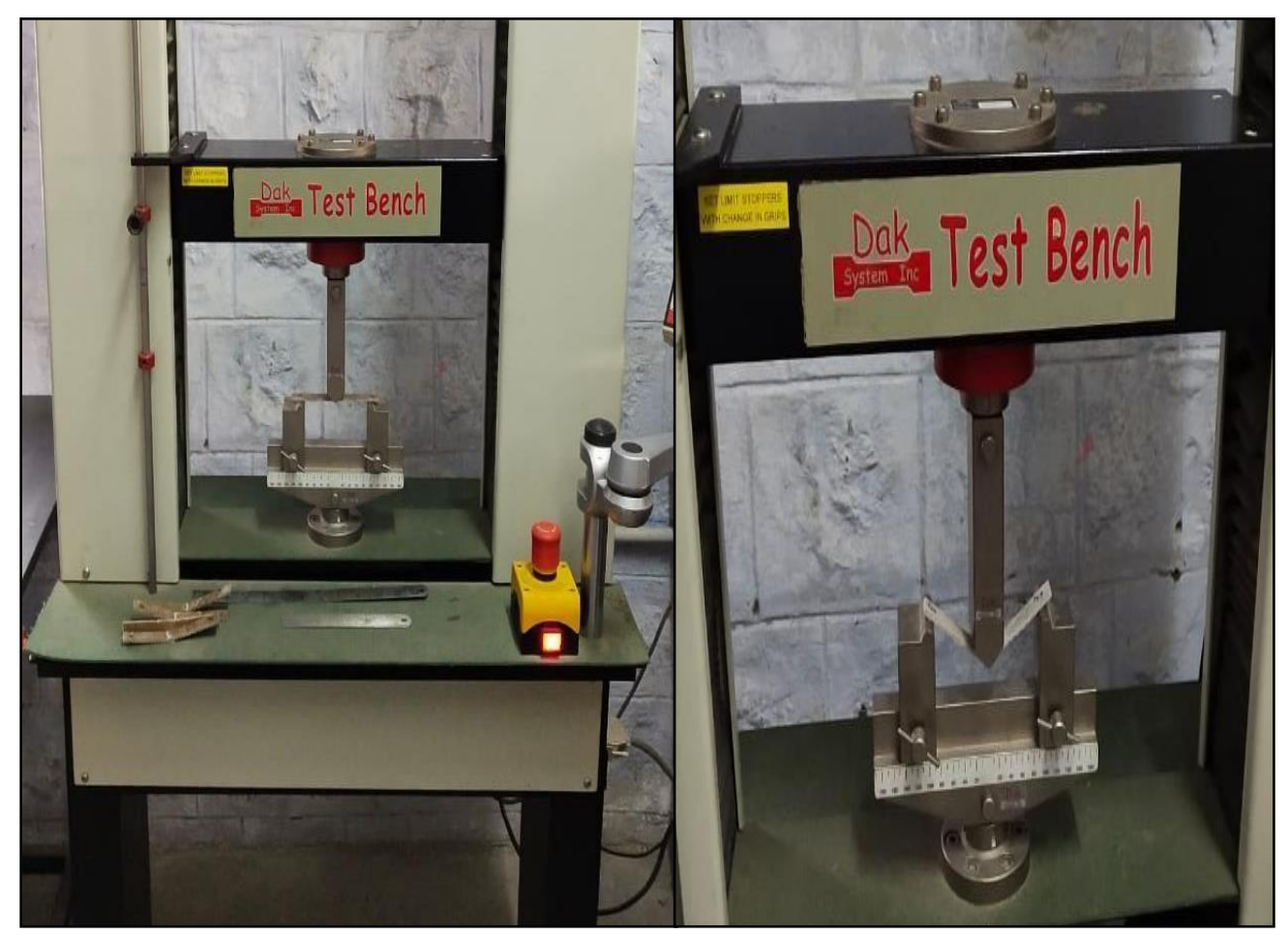

Figure 5 Experimental setup for flexural test 


\section{Impact Test}

Impact test is carried out to determine the amount of energy absorbed by a material during fracture. It is also used to determine the nature of composite, whether they are brittle or ductile? Izod Impact test is employed in determining the impact resistance of composite as per ASTM standard, and it is depicted in Figure 6. Specimen with a notch, which acts as stress concentration point is generally used to determine the impact energy and notch sensitivity. The results are expressed as energy lost (in Joule) per unit of thickness. Figure 7 indicates the experimental setup for flexural testing.
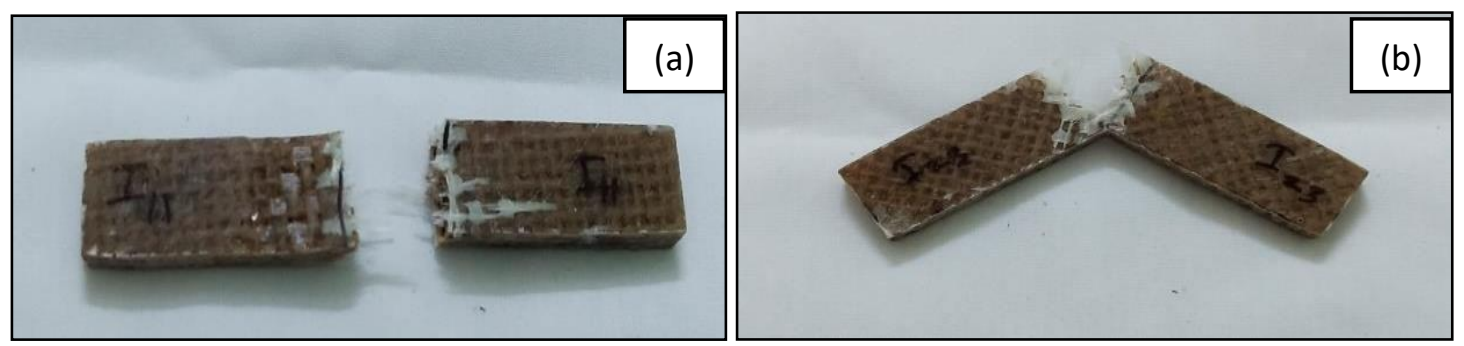

Figure 6 Specimens after impact test a) $90^{\circ}$ orientation b) $45^{\circ}$ orientation

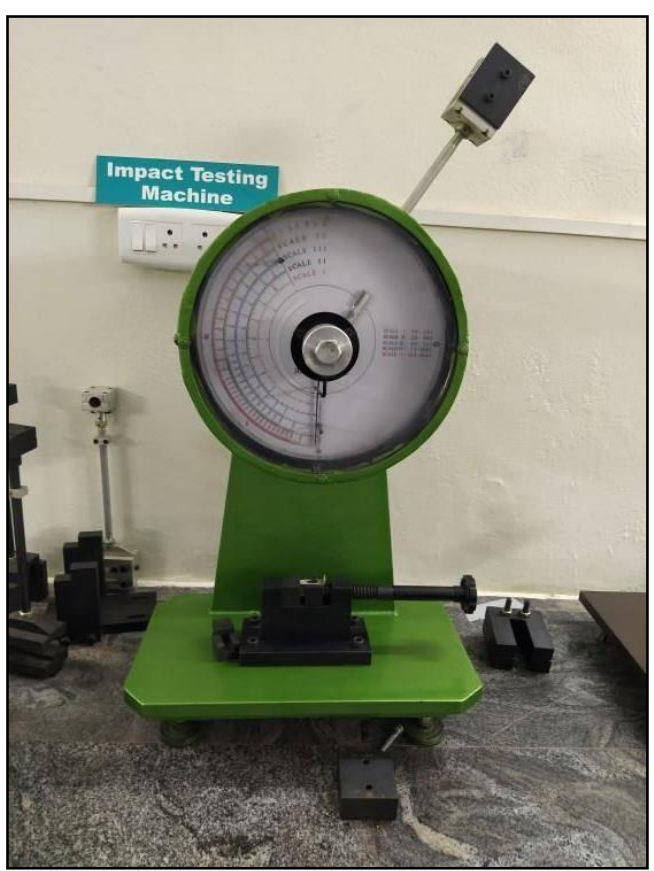

Figure 7 Experimental setup for impact test 


\section{RESULTS AND DISCUSSION}

The mechanical behavior of bi-directional jute and glass fibre hybrid composite material is analyzed both experimentally and analytically.

\section{Mechanical Characteristics of Composites}

\section{Effect of fibre orientation on tensile strength of composites}

The tensile strength decreases with change in fiber orientation. The tensile strength is maximum, when the fibers are oriented along loading direction i.e., $90^{\circ}$ fibre orientation (106 $\mathrm{MPa}$ ). It records $23.52 \%$ more tensile strength than that of the specimen that has $45^{\circ}$ fibre orientation $(84 \mathrm{MPa})$. The combined properties of jute and glass fibers make this happen at $90^{\circ}$ fibre orientation, and similar behavior was recorded in earlier researches by Acharya et al. and Md Koushic Uddin et al.

\section{Fiber orientation effect on Impact Strength}

From the impact test results, it shows that the material with $90^{\circ}$ orientation (3 Joules) shows better impact strength than the $45^{\circ}$ orientation ( 2 Joules). Since the load transfers through the fiber, the $90^{\circ}$ orientation of stacked fibers offer high impact strength compared to $45^{\circ}$ orientation fiber composite. In this way, $90^{\circ}$ oriented composite records $50 \%$ improved impact strength than the other one.

The flexural/bending strength along with the tensile and impact strengths of hybrid composite is exhibited in Table 2. It is understood from the Table 2 that $90^{\circ}$ oriented composite records more flexural strength than the $45^{\circ}$ oriented hybrid composite. Due to the orthogonal alignments of fiber, it withstands more bending load compared to that of at $45^{\circ}$ orientation. Hence, $90^{\circ}$ oriented hybrid composite registers $77.46 \%$ more flexural strength than $45^{\circ}$ oriented hybrid composite. 
Table 2 Mechanical Properties of Jute/Glass hybrid composites

\begin{tabular}{|c|c|c|c|}
\hline $\begin{array}{c}\text { Fiber } \\
\text { orientation }\left({ }^{\circ}\right)\end{array}$ & $\begin{array}{c}\text { Impact strength } \\
(\text { Joules) }\end{array}$ & $\begin{array}{c}\text { Flexural } \\
\text { strength (MPa) }\end{array}$ & $\begin{array}{c}\text { Tensile strength } \\
(\mathbf{M P a})\end{array}$ \\
\hline 45 & 2 & 142 & 84 \\
\hline 90 & 3 & 252 & 106 \\
\hline
\end{tabular}

\section{Structural Analysis}

\section{Tensile strength analysisin ANSYS software}

In this section, a comparison between the fabricated bumper material i.e. jute and glass fiber hybrid composite and existing automobile car bumper is made based on the structural dynamic analysis. For this, the fabricated tensile specimen and an existing car bumper is modeled using CATIA software and analyzed with ANSYS software. From the obtained analytical results from figure 8 , it is evident that the material at $90^{\circ}$ fiber orientation shows a maximum stress of $131 \mathrm{MPa}$ and the material at $45^{\circ}$ fiber orientation shows a maximum stress of $86 \mathrm{MPa}$.
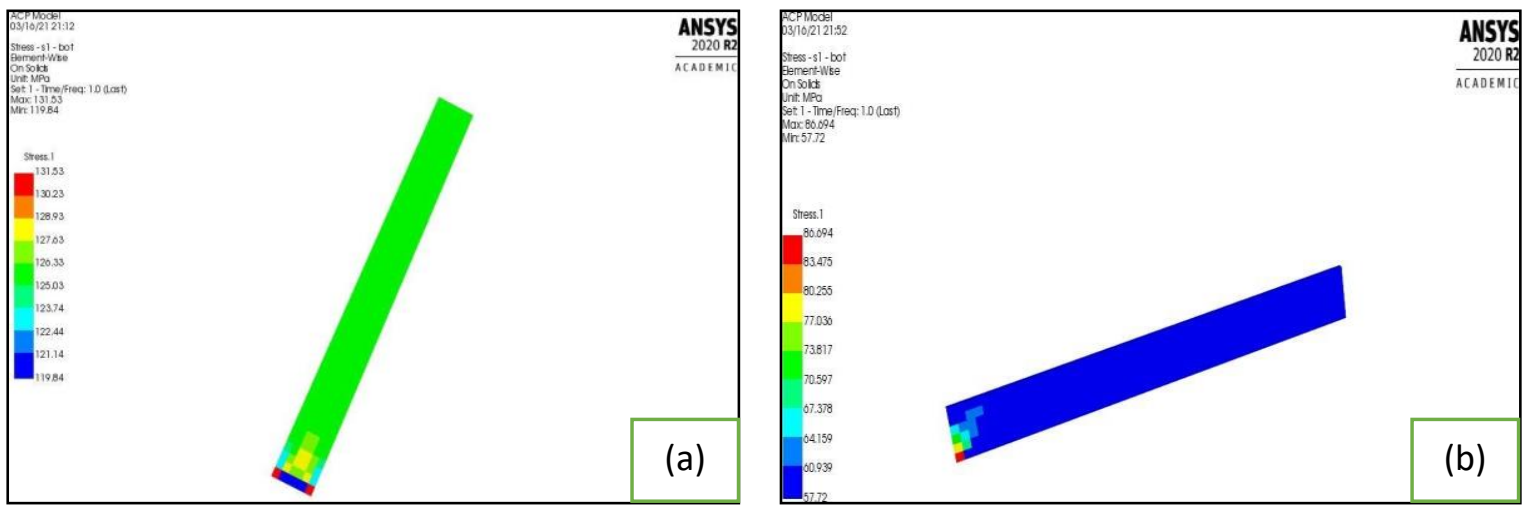

Figure 8 Tensile strength analysis for a) $90^{\circ}$ orientation b) $45^{\circ}$ orientation 
Hence, it is confirmed that a hybrid composite with $90^{\circ}$ fiber orientation offers improved tensile strength.Figure 9 shows isometric and orthographic views of bumper modeled using CATIA software.
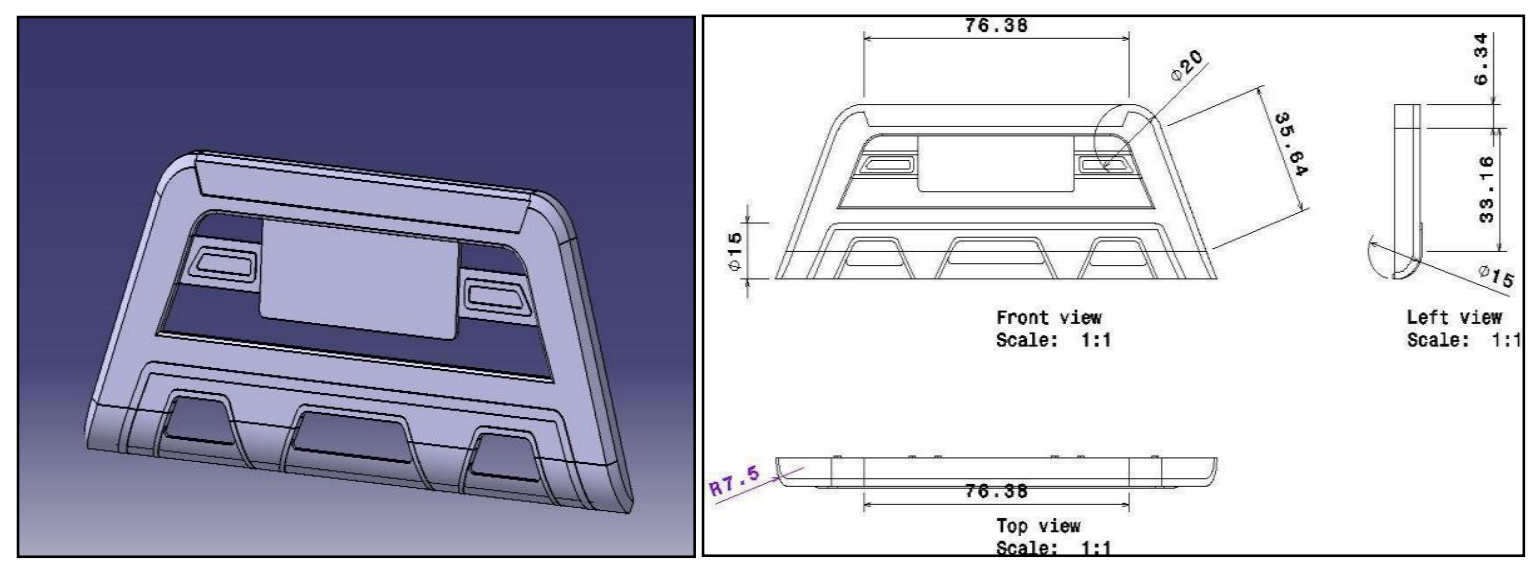

Figure 9 Isometric and orthographic view of bumper

\section{Structural Dynamic analysis of Bumper using ANSYS}

Structural analysis is carried out for Jute/Glass reinforced epoxy composite and existing bumper material (ABS) at two different speeds viz. 75 and $120 \mathrm{kmph}$. The deformation results of are shown in Figure 10.

From the structural analysis, it is clearly seen that $90^{\circ}$ oriented jute/glass fiber composite exhibited improved stress, displacement values than $45^{\circ}$ oriented composite, and when compared to ABS it has offered $69.15 \%$ improved strain which in turn indicates that the proposed fiber hybrid composite is more ductile and offers more deformation that can absorb more impact/shock while collision. Similarly, for the maximum strength it almost matches with the ABS material.

As for as displacement is concerned, $90^{\circ}$ oriented composite records considerably higher value than ABS which again confirms its flexibility that is mandatory in absorbing sudden impact load during collision. As a result, $90^{\circ}$ oriented hybrid composite performs better than the existing ABS material so, jute/glass based hybrid composite with $90^{\circ}$ orientation may be suggested as an alternate bumper material for automobiles in place of ABS. 


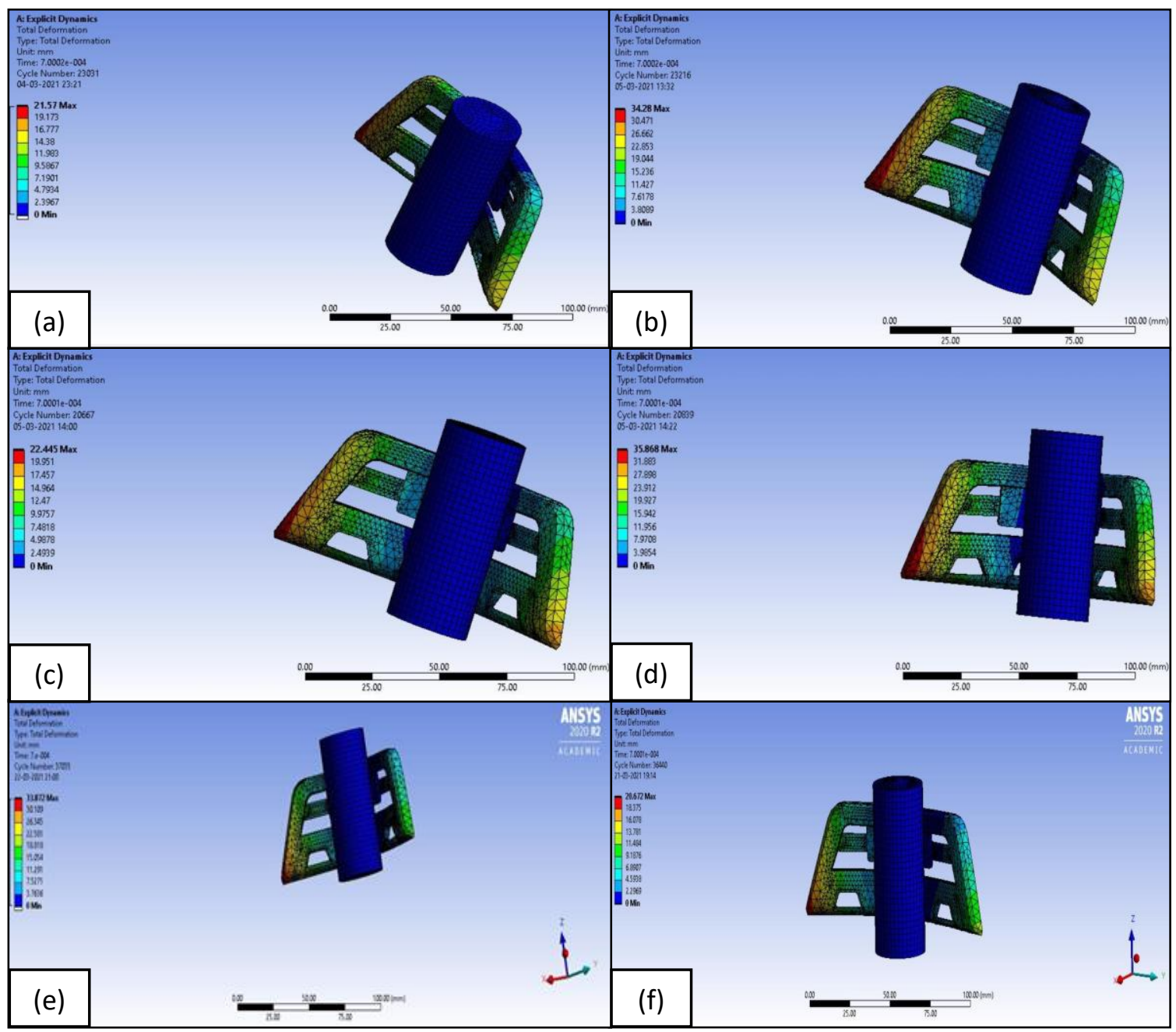

Figure 10 Deformation results of Jute/Glass Fiber a) $90^{\circ}$ at $75 \mathrm{kmph}$, b) $90^{\circ}$ at $120 \mathrm{kmph}$, c) $45^{\circ}$ at $\left.75 \mathrm{kmph}, \mathrm{d}\right) 45^{\circ}$ at $\left.120 \mathrm{kmph}, \mathrm{e}\right) \mathrm{ABS}$ at $\left.75 \mathrm{kmph}, \mathrm{f}\right) \mathrm{ABS}$ at $120 \mathrm{kmph}$.

The detailed comparative tabulated results are presented in Table 3.

Table 3 Comparison of analysis results

\begin{tabular}{|l|c|c|c|c|c|c|}
\hline \multicolumn{1}{|c|}{ Name } & \multicolumn{2}{c|}{$\begin{array}{c}\text { Jute/Glass Fiber } \\
\left(\mathbf{9 0}^{\circ}\right)\end{array}$} & \multicolumn{2}{c|}{$\begin{array}{c}\text { Jute/Glass Fiber } \\
\mathbf{( 4 5}^{\circ} \mathbf{)}\end{array}$} & \multicolumn{2}{c|}{ ABS } \\
\hline Velocity (kmph) & 75 & 120 & 75 & 120 & 75 & 120 \\
\hline Max.Strain & 0.092465 & 0.12966 & 0.086859 & 0.1342 & 0.049768 & 0.076665 \\
\hline Min.Strain & $5.3341 \mathrm{e}^{-8}$ & 0.014407 & 0.009651 & 0.014911 & 0.0055298 & 0.0085183 \\
\hline Max.Stress (MPa) & 115.02 & 161.03 & 87.83 & 132.54 & 105.88 & 167.61 \\
\hline Min.Stress (MPa) & 0.001735 & 17.892 & 9.7592 & 14.727 & 11.76 & 18.62 \\
\hline $\begin{array}{l}\text { Max.Displacement } \\
\text { (mm) }\end{array}$ & 21.57 & 34.28 & 22.445 & 35.868 & 35.868 & 33.872 \\
\hline $\begin{array}{l}\text { Min.Displacement } \\
(\mathrm{mm})\end{array}$ & 2.3967 & 3.8089 & 2.4939 & 3.9854 & 3.9854 & 3.7636 \\
\hline
\end{tabular}




\section{CONCLUSION}

The experimental investigation and analysis of fiber orientation on mechanical properties of jute glass fiber reinforced epoxy hybrid composites are made and the following conclusions are drawn.

- At $90^{\circ}$ fibre orientation, maximum tensile strength of $106 \mathrm{MPa}$ is observed which is $23.52 \%$ more than $45^{\circ}$ fibre oriented composite. In Impact test results, it is obvious that the composite with $90^{\circ}$ orientation (3 Joules) observes more impact strength than $45^{\circ}$ orientation ( 2 Joules). $90^{\circ}$ oriented hybrid composite registers $77.46 \%$ more flexural strength than $45^{\circ}$ oriented hybrid composite since it withstands more bending load on normal axis.

- Structural analysis results shows that $90^{\circ}$ oriented jute/glass fiber composite exhibited improved stress, displacement values than $45^{\circ}$ oriented composite. When compared to ABS, $90^{\circ}$ oriented jute/glass fiber composite has offered $69.15 \%$ improved strain and confirms that it has more ductility to absorb more shock.

- As a result, $90^{\circ}$ oriented hybrid composite performs better than the existing ABS material so, jute/glass-based hybrid composite with $90^{\circ}$ orientation may be suggested as an alternate bumper material for automobiles in place of ABS. 


\section{REFERENCES}

John, M. J., \&Anandjiwala, R. D. 2008. Recent developments in chemical modification and characterization of natural fibre-reinforced composites. Polymer composites. 29(2): 187207.

Biswas S., Kindo S., Patnaik A., 2011. Effect of Length on Coir Fibre Reinforced Epoxy Composites. Fibre and Polymers. 12: 73-78.

Sanjay M.R., Arpitha G.R., B. Yogesha. 2015. Study on Mechanical Properties of Natural Glass Fibre Reinforced Polymer Hybrid Composites.Materials Today: Proceedings. 2: 2959-2967.

Sharmin K., Alam J., M. W. Dewan. 2019. Fabrication and characterization of Jute/Glass Fiber reinforced epoxy hybrid composites. Journal of Mechanical Engineering. 49 (2): 2327.

Sergio Monteiro, Luis Hernandez Terrones, José Roberto d'Almeida. 2008. Mechanical performance of coir fibre/polyester composites. Polymer Testing, 27(5):591- 595.

Acharya, Bera T., Prakash V., Pradhan S. 2019. Effect of stacking sequence on the tribological behaviour of jute-glass hybrid epoxy composite, Materials Today: Proceedings. 28 (2): 1-4.

Chawla, K. K. \& Bastos, A. C. 1979. The mechanical properties of jute fibres and polyester/jute composites. In: Proceedings of the third international conference on mechanical behaviour of materials. Cambridge, UK: Pergamon Press, pp. 191-196.

Braga, P.A.A. Magalhaes Jr. 2015. Analysis of the mechanical and thermal properties of jute and glass fiber as reinforcement epoxy hybrid composites.Materials Science and Engineering: C.56: 269-273.

Chandekar H., Chaudhari V., Waigaonkar S. 2020. A review of Jute fiber Reinforced polymer composites.Materials Today: Proceedings. 26 (2):2079-2082.

Dehury J., Behera A., Biswas S. 2020.A Study on the Mechanical behavior of Jute- Epoxy Laminated Composite and its Hybrid.Material Science Forum. 978: 250 -256.

Md. Rafiquzzaman, M. Zannat, R. Roy, Mst Nazma Sultana. 2018. Jute-Glass Fiber Based Composite for Engineering Application.European Journal of Advances in Engineering \& Technology. 4: 510-515.

Indra M., P. Varma, A. Kumar, V. Manikanth, K. Raju. 2018. Comparative Evaluation on Mechanical Properties of Jute, Pineapple leaf fiber and Glass Fiber reinforced composites with Polyester and Epoxy Resin Matrices.Materials Today: Proceedings.5 (2): 5649-5654.

Md Koushic Uddin, Muksit Ahmed Chowdhury, S. Hossain, Md. Zahidul Islam. 2020. Investigation on mechanical properties and water absorbency of jute Glass reinforced epoxy composite. Journal of Textile Engineering and Fashion Technology. 6 (5): 190- 197.

P. Kumar, K. Ram, L. Kumar, V. Kumar. 2018. Fabrication of Glass/Jute/Epoxy Composite Based Industrial Safety Helmet.Materials Today: Proceedings. 5 (2): 8699 8706.

Dilfi A., A. Balan, Hong Bin, Guijun Xian, Sabu Thomas. 2018. Effect of Surface Modification of Jute Fiber on the Mechanical Properties and Durability of Jute FiberReinforced Epoxy Composites.Polymer Composites. 39 (S4):E2519-E2528.

Harpreet S., P. Singh, S. Singh, V. Dhawan, K. Tiwari. 2018. A Brief Review of Jute Fibre and Its Composites.Materials Today: Proceedings. 5 (14): 28427 -28437. 
H. Wang, H. Memon, A.M. Hassan, Md. Sohag Miah, Md. Arshad Ali. 2019. Effect of Jute Fiber Modification on Mechanical Properties of Jute Fiber Composite.Materials (Basel). 12(8): 1226, 1-11.

Indra R., A. Kumar, Ch. Rama Bhadri Raju. 2018. Tensile and Flexural properties of Jute, Pineapple leaf and Glass Fiber Reinforced Polymer Matrix Hybrid Composites.Materials Today: Proceedings. 5 (1): 458-462. 